\title{
Case volume and mortality in haematological patients with acute respiratory failure
}

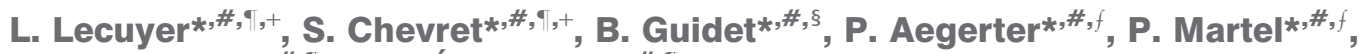

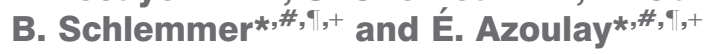

ABSTRACT: High case volume is associated with improved survival in medical and surgical conditions. The present study sought to determine whether intensive care unit (ICU) case volume was associated with survival of critically ill patients with haematological malignancies and acute respiratory failure (ARF).

A regional database containing data from 1,753 haematological patients with ARF admitted to 28 medical ICUs from 1997 to 2004 was used. Multivariate analysis using mixed models was performed to adjust for severity of illness and other confounding factors, including a propensity score that incorporates differences between ICUs with different case volumes.

The three case volume tertiles were: low volume ( $<12$ admissions per year), intermediate volume (12-30 admissions per year), and high volume ( $>30$ admissions per year). In univariate analyses, ICU case volume was not associated with ICU mortality. After adjusting for prognostic factors for ICU mortality and the propensity score, patients in high-volume ICUs had lower mortality than other patients. A case volume increase of one admission per year led to a significant mortality reduction with an odds ratio of 0.98 (95\% confidence limits $0.97-0.99$ ). Mortality was independently associated with severity of organ dysfunction.

In intensive care units admitting larger numbers of critically ill haematological patients with acute respiratory failure, mortality was lower than in other intensive care units. The mechanisms of the relationship between volume and outcome among haematological patients with acute respiratory deserve additional studies.

KEYWORDS: Acute leukaemia, bone marrow transplant, lymphoma, mechanical ventilation, myeloma, neutropenia

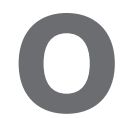

ver the last 20 yrs, substantial diagnostic and therapeutic advances have increased overall and disease-free survivals in patients with haematological malignancies [1]. Agents targeting the pathophysiological mechanisms of haematological malignancies [2, 3], increases in the intensity and duration of lifespanextending cancer treatments [4] and more widespread use of allogeneic bone marrow transplantation [5] contribute to the survival gains, but also cause life-threatening toxic and infectious complications. As a result, the number of haematological patients admitted to the intensive care unit (ICU) is increasing $[6,7]$.

Acute respiratory failure (ARF) is the main reason for ICU admission of patients with haematological malignancies [7-9]. ARF occurs in 10-20\% of patients with acute leukaemia or lymphoma and in about half the patients with neutropenia or bone marrow transplantation [10, 11]. ARF in haematological patients is a dreaded event that is fatal in up to $50 \%$ of cases, with the highest mortality rates occurring among patients with allogeneic bone marrow transplantation or mechanical ventilation [8-13]. Furthermore, failure to identify the pathogen causing pulmonary infiltrates in haematology patients with ARF is associated with a decreased survival [10, 11, 14]. Clinical experience (with both haematological malignancies and ARF) and knowledge of the literature may aid recognition of specific infectious diseases, drug-related toxicities, the many complex factors contributing to noninfectious pulmonary involvement, and the frequent intertwining of multiple disease processes in individual patients [10]. Clinical experience is related to case volume, suggesting that survival might be better in high-volume ICUs.

\section{AFFILIATIONS}

*Intensive Care Unit and Biostatistics Dept, Saint-Louis Teaching Hospital,

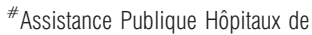
Paris,

University Paris 7 +U717 Inserm,

§Intensive Care Unit, Saint-Antoine Teaching Hospital, and

${ }^{f}$ Biostatistics Dept, Ambroise Paré Teaching Hospital, Paris, France.

\section{CORRESPONDENCE}

É. Azoulay

Service de Réanimation Médicale

Hôpital Saint-Louis

1 avenue Claude Vellefaux

75010 Paris

France

Fax: 33142499426

E-mail: elie.azoulay@sls.

ap-hop-paris.fr

Received:

October 292007

Accepted after revision:

March 292008

SUPPORT STATEMENT

This study was supported by a grant

from the nonprofit institution

Assistance-Publique Hôpitaux de

Paris (AOM 04139).

STATEMENT OF INTEREST

A statement of interest for É. Azoulay can be found at www.erj. ersjournals.com/misc/statements. shtml

Online ISSN 1399-3003 
An association between the number of patients with a specific condition treated in a hospital (hospital volume) and outcomes in these patients has been reported for numerous medical and surgical conditions [15], including ARF treated with mechanical ventilation [16]. This volume-outcome relationship may either stem from a beneficial effect of greater provider experience or from selective referral to providers who obtain better outcomes. The current authors hypothesised that higher case volume is associated with better survival in ICU patients with haematological malignancies and ARF.

The purpose of the present study was to examine the relationship between ICU volume and survival among critically ill haematology patients with ARF. Therefore, data from a regional database in the Paris area of France was used to examine mortality rates according to case volume.

\section{PATIENTS AND METHODS}

Database characteristics

In 1992, the French Society for Critical Care (Société de Réanimation de Langue Française) sponsored the creation of a regional database, the Collège des Utilisateurs de Bases de données en Réanimation (CUB-Réa) Network, in the urban area of Paris (France). The number of participating ICUs reached 33 in 1997, 37 in 2000, and 35 in 2004. The variables to be recorded have been defined and definitions for each variable created. All data were recorded prospectively in each ICU using standardised database software. Coding methods are harmonised during annual meetings. The database quality has been assessed in a previous study [17]. Recorded variables are shown in table 1 . The simplified acute physiology score (SAPS) II is recorded within $24 \mathrm{~h}$ of ICU admission [18]; the use of life-sustaining therapies (dialysis, vasopressors and mechanical ventilation) is collected throughout the ICU stay. Neutropenia is defined as a total leukocyte count $<1,000 \mathrm{~mm}^{-3}$. Close neurological monitoring includes repeated clinical evaluations, lumbar puncture, electroencephalogram and cerebral magnetic resonance imaging. Vital status is collected at ICU discharge. For the present study, the data used was entered into the database during the first 8 yrs, i.e. from 1997 to 2004.

\section{Eligibility criteria}

Only data from ICUs that participated continuously in the CUB-Rea database for 8 yrs were used. Among patients in the database, adults with haematological malignancies who were

TABLE 1 Factors associated with intensive care unit (ICU) mortality

\begin{tabular}{|c|c|c|c|c|}
\hline & Survivors & Decedents & OR $(95 \% \mathrm{Cl})$ & p-value \\
\hline Subjects & $1041(59.38)$ & $712(40.62)$ & & \\
\hline Males & $607(58.30)$ & $448(62.92)$ & $1.24(1.02-1.51)$ & 0.03 \\
\hline University hospital & $878(84.34)$ & $578(81.17)$ & $0.90(0.57-1.42)$ & 0.64 \\
\hline Haematology ward in the hospital & $822(78.96)$ & $536(75.28)$ & $0.99(0.64-1.52)$ & 0.95 \\
\hline Home & $296(28.43)$ & $179(25.14)$ & 1.00 & \\
\hline Hospital ward & 607 (58.30) & 419 (58.84) & $1.19(0.94-1.51)$ & 0.12 \\
\hline Other hospital & $138(13.25)$ & $114(16.01)$ & $1.20(0.87-1.63)$ & 0.26 \\
\hline Acute leukaemia & $263(25.26)$ & $216(30.33)$ & $1.30(1.05-1.62)$ & 0.01 \\
\hline Non-Hodgkin lymphoma & 299 (28.72) & $211(29.63)$ & $1.03(0.83-1.27)$ & 0.74 \\
\hline \multicolumn{5}{|l|}{ Organ failures and life-sustaining therapies } \\
\hline Need for noninvasive mechanical ventilation & $311(29.87)$ & $170(23.87)$ & $0.74(0.60-0.92)$ & 0.01 \\
\hline Need for invasive mechanical ventilation ${ }^{+}$ & $322(30.93)$ & $645(90.58)$ & $21.54(16.37-28.54)$ & $<0.0001$ \\
\hline Criteria for ARDS & $50(4.80)$ & $153(21.48)$ & $6.23(4.38-8.87)$ & $<0.0001$ \\
\hline Length of mechanical ventilation & $2.90 \pm 8.04$ & $6.61 \pm 9.54$ & $1.05(1.03-1.06)$ & $<0.0001$ \\
\hline Presence of shock & $201(19.30)$ & $496(69.66)$ & $9.87(7.80-12.49)$ & $<0.0001$ \\
\hline Need for vasopressors & $273(26.22)$ & 579 (81.32) & $12.55(9.92-15.88)$ & $<0.0001$ \\
\hline Acute renal failure & $217(20.84)$ & $378(53.08)$ & $5.58(4.16-7.49)$ & $<0.0001$ \\
\hline Need for renal replacement therapy & $74(7.10)$ & $213(29.91)$ & $4.17(3.36-5.18)$ & $<0.0001$ \\
\hline Coma & $60(5.76)$ & $146(20.50)$ & $4.13(3.02-5.66)$ & $<0.0001$ \\
\hline Close neurological monitoring & $228(21.90)$ & 237 (33.28) & $1.85(1.49-2.30)$ & $<0.0001$ \\
\hline ICU length of stay & $7.97 \pm 11.19$ & $8.59 \pm 10.88$ & $1.00(0.99-1.01)$ & 0.50 \\
\hline
\end{tabular}

Data are presented as $\mathrm{n}(\%)$ or mean $\pm \mathrm{SD}$, unless otherwise stated. A univariable mixed regression model was used. OR: odds ratio; Cl: confidence interval; BAL: bronchoalveolar lavage; SAPS II: simplified acute physiology score version II; ARDS: acute respiratory distress syndrome. ${ }^{*}$ : per year; ${ }^{*}$ : per point; ${ }^{+}$: some patients received both mechanical ventilation and noninvasive mechanical ventilation. 
TABLE 2 Description of the study cohort according to year of intensive care unit admission

\begin{tabular}{|c|c|c|c|c|c|c|}
\hline Year & ARF-H n & ARF-H-MV & Admissions from home & Neutropenia & Bone marrow transplant & Death \% \\
\hline 1997 & 149 & $69(46.30)$ & $29(19.46)$ & $37(24.83)$ & $19(12.75)$ & 34.9 \\
\hline 1999 & 216 & $116(53.70)$ & $55(25.46)$ & $91(42.12)$ & $26(12.03)$ & 44.0 \\
\hline 2000 & 207 & $100(48.30)$ & $51(24.63)$ & $83(40.09)$ & $20(9.66)$ & 37.3 \\
\hline 2001 & 188 & $98(52.12)$ & $64(34.04)$ & $88(42.51)$ & $12(6.38)$ & 41.5 \\
\hline 2004 & 308 & $224(72.72)$ & $98(31.81)$ & $18(5.84)$ & $23(7.46)$ & 42.5 \\
\hline Total & 1753 & $967(55.16)$ & $475(27.09)$ & $573(32.68)$ & $157(8.95)$ & $712(40.6)$ \\
\hline
\end{tabular}

Data are presented as $\mathrm{n}(\%)$, unless otherwise stated. ARF-H: overall population of patients with acute respiratory failure and haematological malignancies; ARF-H-MV: subgroup of patients who required invasive mechanical ventilation.

admitted to these medical ICUs for ARF were identified. Patients admitted after emergency or scheduled surgery were excluded. Patients with AIDS were also excluded.

\section{ICU volumes}

To measure the volume of critically ill haematological patients with ARF, annual estimators were used based on either the number of admissions per year (1997-2004) or the cumulative annual mean number of admissions during the study period. For instance, the cumulative annual mean number of admissions for 1998 was the total number of patients admitted to that ICU before and in 1998 (i.e. in 1997 and 1998) divided by two, and the 1999 ICU cumulative mean number was the total number of patients admitted in that ICU before and in 1999 (i.e. in 1997, 1998 and 1999) divided by three. The annual prevalence of critically ill haematological patients with ARF was similarly computed by dividing volume estimates (number of admissions of haematological patients with ARF and cumulative annual mean number of admissions) by the corresponding number of total admissions.

\section{Statistical analysis}

To study the period effect on ICU mortality, the current authors relied on a nonparametric estimate of the shape of the mortality rate curve over the study period. This allowed identification of dates that distinguished periods characterised by different mortality rates.

To analyse the volume-outcome relationship, funnel plots of observed annual mortality rates against case volume were created, in which the target was the overall mean mortality rate in the study cohort [19]. Control limits, based on quantile functions for the binomial distribution, allowed identification of ICUs that differed significantly from the target, as defined by a two-sided p-value $<0.05$ (corresponding to $1.96 \times$ SD from the target). Spearman correlation coefficients between ICU volume and mortality rate were computed. Following this, individual patient data were used to build regression models in which the dependent variable was ICU mortality and the independent variables were ICU volumes and potential predictors of ICU mortality (table 1). Moreover, given the potential for a centre effect, mixed models were used [20, 21]. Univariate analyses were performed and factors associated with the outcome at the $20 \%$ level were entered into the multivariate analysis. The final model included only prognostic variables that were statistically significant at the $\alpha / \mathrm{k}$ level, determined by dividing the error rate $\alpha=0.05$ by the number $(\mathrm{k}=16)$ of variables entered into the multivariate model [22, 23]. To estimate the effect of volume on mortality, adjusted for the prognostic variables selected so far, the variable was forced into the final multivariate mixed model. Finally, to better incorporate differences in baseline characteristics of patients

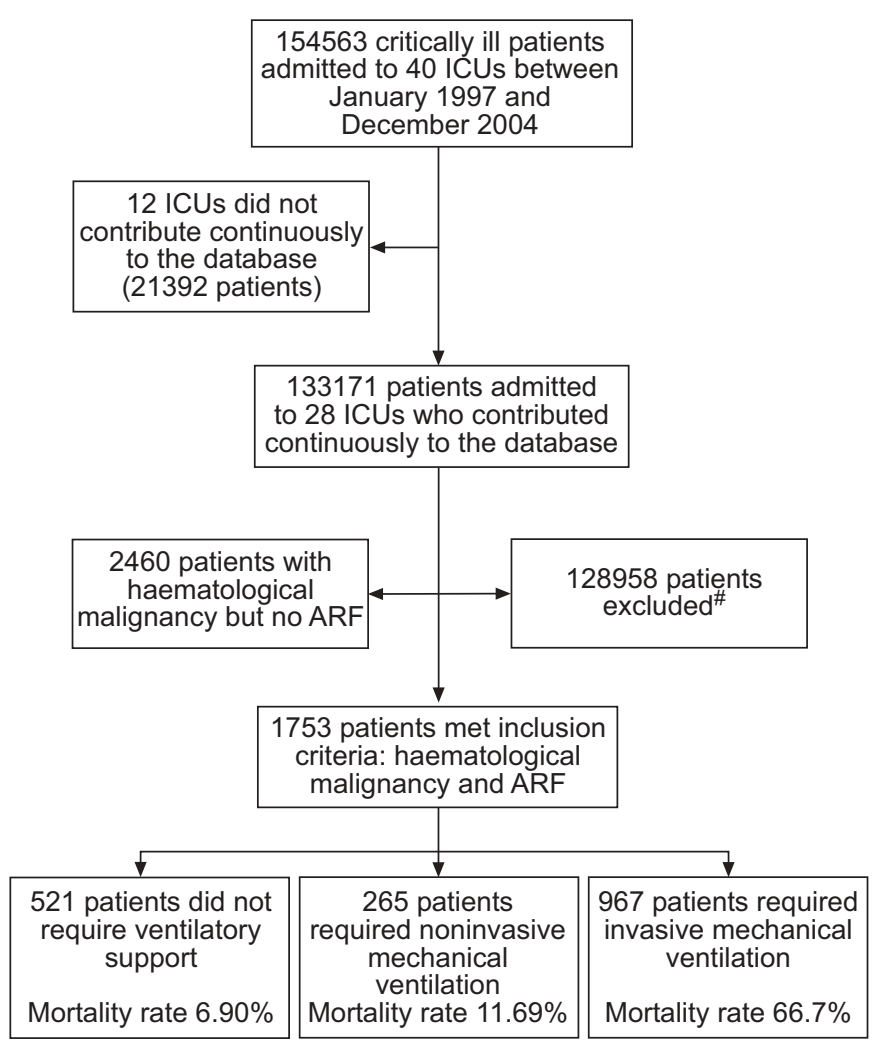

FIGURE 1. Patient flow chart. ICU: intensive care unit; ARF: acute respiratory failure. ${ }^{*}$ : 97,542 patients with no haematological malignancy, 3,655 with AIDS, 27,735 surgical patients and 26 aged $<18$ yrs. 


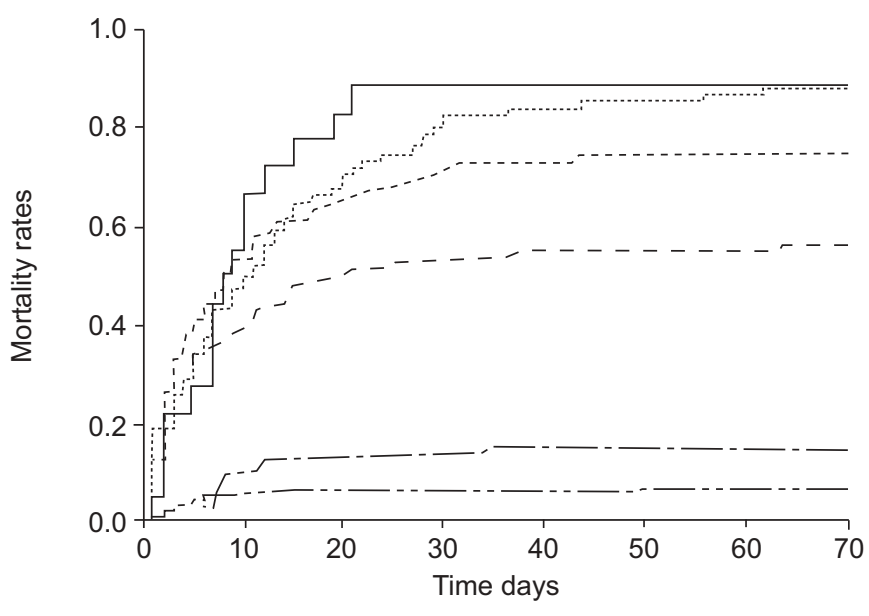

FIGURE 2. Mortality rates according to the number of organ failures. Organ failures were haematological (neutropenia), renal (renal replacement therapy), respiratory (invasive mechanical ventilation), cardiovascular (vasopressors) and neurological (coma). $\cdot \cdots+\cdots \cdot \cdots$ no organ failures; $\cdot-\cdot \cdot \cdot$ : one organ failure: - - - - -: two organ failures; - - . - -: three organ failures; $\cdots \cdots$ : four organ failures; _ five organ failures.

admitted to ICUs in each of the three ICU case volume tertiles (high volume $>30$ admissions per year; intermediate volume $12-30$ admissions per year; and low volume $<12$ admissions per year), a propensity score was developed for the category of the admitting ICU and the value of this score was incorporated into the previous model $[24,25]$. The propensity score was derived from an odds proportional regression model with volume category as the dependent variable. All available patient characteristics at ICU admission (age, sex, SAPS II,

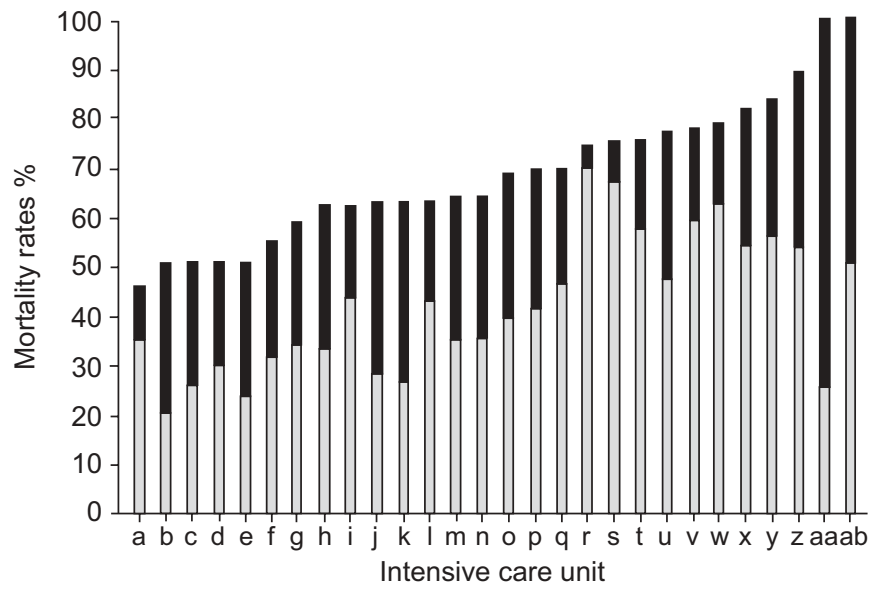

FIGURE 3. Mortality rates across participating intensive care units 口: haematological patients with acute respiratory failure (ARF) requiring invasive mechanical ventilation; 1 : haematological patients with ARF (all patients).

cancer status, bone marrow transplant status, acute leukaemia status and non-Hodgkin lymphoma status) were screened for inclusion in the model and the propensity score was then estimated for each patient. The final propensity score model included only those variables that were statistically significant at the corrected level as indicated above (with $\mathrm{k}=6$ ).

\section{RESULTS}

Between January 1997 and December 2004, a total of 154,563 patients were consecutively admitted to the medical ICUs participating in the database. The patient flow chart is shown in figure 1. Among the 4,213 critically ill haematological

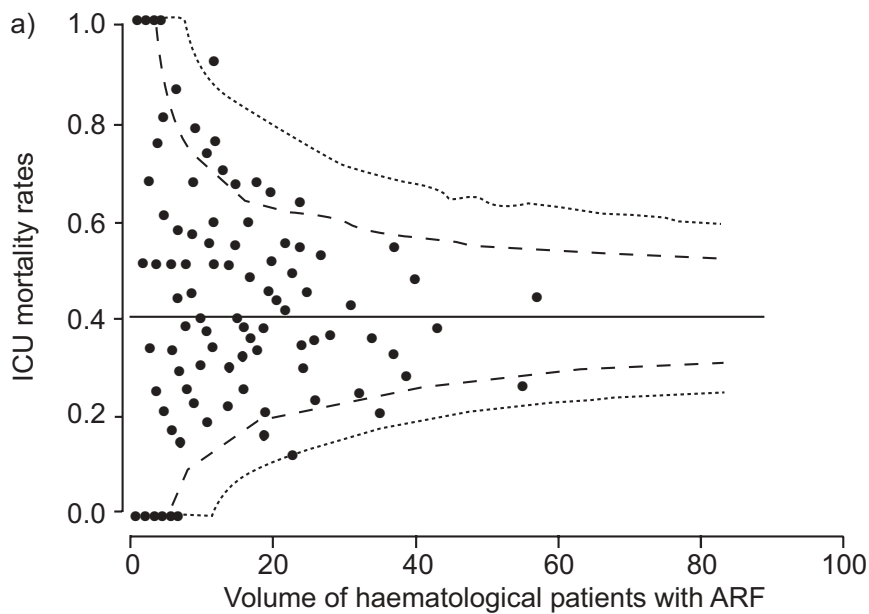

b)

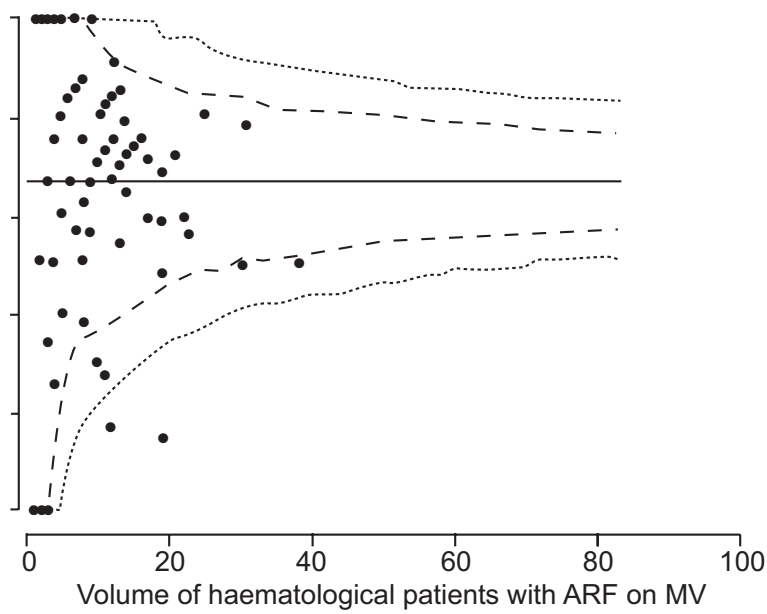

FIGURE 4. Funnel plots of observed annual mortality rates in patients with haematological malignancies according to the use of invasive mechanical ventilation. a) Intensive care unit (ICU) mortality in 28 French ICUs, 1997-2004. Funnel plots of the observed annual mortality against case volume of acute respiratory failure (ARF) patients. No statistically significant correlation was observed between case volume and mortality (Spearman coefficient $-0.06,95 \%$ confidence interval $-0.20-0.09 ; p=0.44$ ). b) ICU mortality in 28 French ICUs, 1997-2004. Funnel plots of the observed annual mortality against case volume of ARF patients undergoing mechanical ventilation (MV) No statistically significant correlation was observed between case volume and mortality (Spearman coefficient $-0.001,95 \%$ confidence interval $-0.15-0.15 ; p=0.99$ ) Equations used were as follows. $X_{i j}$ is the number of haematological patients with ARF during year i in ICU j. $Y_{i j}$ is the number of patients admitted in ICU $j$ in year $i$. The annual volume of haematological patients with ARF in year $i$ and ICU $j$ is $X_{i j}$. The annual prevalence of haematological patients with ARF in year $i$ and ICU $j$ is $X_{i j} Y_{i j}$. The cumulative annual volume of haematological patients with ARF in year $i+2$ and ICU $j$ is $\left.\left(X_{-i j}+X_{i+1+}+X_{i+2 i}\right) /\left(i_{+2}-i\right)+1\right)$. The cumulative annual prevalence of haematological patients with ARF in year i+2 and ICU j is $\left(\left(X_{i j}+X_{i+1 j}+X_{i+2 i}\right) /\left(\left(i_{+2}-i\right)+1\right)\right) /\left(\left(Y_{i j}+Y_{i+1 j}+Y_{i+2 j}\right) /\left(\left(i_{+2}-i\right)+1\right)\right)=\left(X_{i j}+X_{i+1 j}+X_{i+2 j}\right) /\left(Y_{i j}+Y_{i+1 j}+Y_{i+2 j}\right)$. 


\begin{tabular}{lll} 
TABLE 3 & $\begin{array}{l}\text { Factors associated with intensive care unit }(\mathrm{ICU}) \\
\text { mortality: results of the multivariate mixed } \\
\text { regression model }\end{array}$ & \\
& OR (95\% CI) & p-value \\
\hline & $1.02(1.01-1.03)$ & $<0.0001$ \\
SAPS II score at ICU admission & $7.17(5.03-10.20)$ & $<0.0001$ \\
Mechanical ventilation & $2.66(1.73-4.10)$ & $<0.0001$ \\
Criteria for ARDS & $2.43(1.77-3.33)$ & $<0.0001$ \\
Shock & $2.94(2.15-4.02)$ & $<0.0001$ \\
Need for vasopressors & $2.36(2.15-4.02)$ & $<0.0001$ \\
Coma & $2.07(1.42-3.01)$ & $<0.0001$ \\
Need for renal replacement therapy & $0.98(0.96-0.99)$ & $<0.0001$ \\
Length of mechanical ventilation days & & \\
\hline
\end{tabular}

OR: odds ratio; Cl: confidence interval; SAPS II: simplified acute physiology score version II; ARDS: acute respiratory distress syndrome.

patients, 1,753 (41.60\%) were admitted for ARF and form the basis of the present study. Table 1 reports patient characteristics. Acute leukaemia and non-Hodgkin lymphoma were the main haematological malignancies. There were 157 (8.96\%) bone marrow transplant recipients and 573 (32.68\%) patients with neutropenia. Approximately one-quarter of the patients were admitted directly to the ICU from home. The SAPS II score was $54.00 \pm 23.89$, indicating an expected survival rate of $44.67 \%$. Ventilatory support was needed in 1,232 (70.27\%) patients and consisted of noninvasive mechanical ventilation in $481(27.43 \%)$ patients and invasive mechanical ventilation in $967(55.16 \%)$ patients. ICU length of stay was $8.22 \pm 11.07$ days and ICU mortality was 40.61\% (712 deaths). In 67 (9.41\%) patients, a decision to withhold mechanical ventilation was implemented; all these patients died in the ICU. As reported in table 2, ICU admissions and the use of mechanical ventilation increased over the study period. However, mortality remained stable over time. Figure 2 shows mortality rates according to the number of organ failures, figure 3 shows mortality rates across study ICUs, and figure 4 shows the relationship between case volume and mortality. No significant correlation between ICU volume and mortality was observed.

As shown in table 3, severity at ICU admission, number of organ failures and use of life-sustaining therapies were independent predictors of mortality. In addition, in patients requiring ventilatory support, mortality was lower when noninvasive mechanical ventilation was used instead of invasive mechanical ventilation (fig. 1). Table 4 reports the variables associated with the propensity for admission to low-, intermediate- or high-volume ICUs. The multivariate model identified six variables associated with volume category of the admitting ICU: age, acute leukaemia, bone marrow transplant, solid tumour, patient location before admission and SAPS II. Patients admitted to high-volume ICUs were younger, more likely to have acute leukaemia or non-Hodgkin lymphoma, less likely to have solid tumours and less likely to be admitted from home.

As reported in table 5, the annual volume of critically ill haematological patients with ARF was associated with ICU mortality after adjustment for the prognostic factors and propensity score. For instance, a volume difference of 10 patients per year was associated with an odds ratio for death of 0.808 in the high-volume ICUs.

\section{DISCUSSION}

The present study is the first to show that critically ill haematological patients with ARF have a better chance of survival in ICUs admitting higher volumes of such patients. Using a large database containing 1,753 critically ill haematological patients with ARF admitted to 28 ICUs, it was found that the annual volume of such patients independently affected mortality (taking into account centre effect and other independent predictors of mortality, as well as differences in ICUs populations admitted to each volume category (high, intermediate and low), via a propensity score).

TABLE 4 Variables associated with the propensity for admission to a low-, intermediate- or high-volume intensive care unit (ICU)

\begin{tabular}{|c|c|c|c|c|c|}
\hline & \multicolumn{3}{|c|}{ ICU admissions } & \multicolumn{2}{|c|}{ Multivariate odds proportional model } \\
\hline Age yrs & $62.84 \pm 16.21$ & $56.81 \pm 16.34$ & $52.28 \pm 16.52$ & $0.98(0.97-0.99)$ & $<0.0001$ \\
\hline Acute leukaemia & $92(16.72)$ & $245(32.11)$ & $142(32.27)$ & $1.89(1.52-2.35)$ & $<0.0001$ \\
\hline Bone marrow transplant & $13(2.36)$ & $56(7.33)$ & $88(20)$ & $4.17(2.93-5.94)$ & $<0.0001$ \\
\hline Concomitant solid tumour & $38(6.9)$ & $26(3.4)$ & $10(2.3)$ & $0.50(0.31-0.78)$ & 0.003 \\
\hline Admission from hospital ward & $276(50.18)$ & $495(64.8)$ & $255(57.95)$ & $1.33(1.09-1.62)$ & 0.006 \\
\hline Admission from other hospital & $74(13.45)$ & $95(12.45)$ & $83(18.86)$ & $1.58(1.18-2.12)$ & 0.002 \\
\hline SAPS II & $54.02 \pm 23.33$ & $55.99 \pm 24.84$ & $50.53 \pm 22.53$ & & NS \\
\hline Males & $335(60.90)$ & $455(59.63)$ & $265(60.22)$ & & NS \\
\hline
\end{tabular}

Data are presented as $n(\%)$ or mean $\pm \mathrm{SD}$, unless otherwise stated. Volume is defined as the number of patients with haematological malignancies and acute respiratory failure admitted to the intensive care unit each year. Low volume: $<12$ patients per year; intermediate volume: 12-30 patients per year; high volume: $>30$ patients per year. OR: odds ratio; Cl: confidence interval; SAPS II: simplified acute physiology score version II; NS: nonsignificant. 


\begin{tabular}{|c|c|c|c|}
\hline \multirow[t]{2}{*}{ TABLE 5} & \multicolumn{3}{|c|}{$\begin{array}{l}\text { Estimates of volume effect on intensive care unit } \\
\text { mortality from mixed regression models } \\
\text { incorporating centre effect }\end{array}$} \\
\hline & & OR (95\% Cl) & p-value \\
\hline \multicolumn{4}{|c|}{ Unadjusted estimates } \\
\hline Annual volu & & $0.998(0.98-1.007)$ & 0.70 \\
\hline Prevalence & & $1.003(0.98-1.02)$ & 0.83 \\
\hline Cumulative & innual volume & $1(0.98-1.02)$ & 1 \\
\hline Cumulative & annual prevalence \% & $1.005(0.97-1.09)$ & 0.62 \\
\hline \multicolumn{4}{|c|}{ Estimates adjusted on prognostic set ${ }^{\#}$} \\
\hline Annual volu & & $0.98(0.97-0.99)$ & 0.008 \\
\hline Prevalence & & $1.00(0.98-1.02)$ & 0.93 \\
\hline Cumulative & innual volume & $0.99(0.97-1.01)$ & 0.24 \\
\hline Cumulative & nnual prevalence $\%$ & $1.002(0.98-1.02)$ & 0.90 \\
\hline \multicolumn{4}{|c|}{$\begin{array}{l}\text { Estimates adjusted on prognostic set } \\
\text { and propensity score }\end{array}$} \\
\hline Annual volt & & $0.98(0.97-0.99)$ & 0.002 \\
\hline Prevalence & & $0.997(0.97-1.01)$ & 0.80 \\
\hline Cumulative & innual volume & $0.99(0.97-1.01)$ & 0.10 \\
\hline Cumulative & annual prevalence \% & $1.00(0.97-1.03)$ & 0.96 \\
\hline
\end{tabular}

Each measure of volume is analysed separately. OR: odds ratio; Cl: confidence interval. ${ }^{*}$ : simplified acute physiology score (SAPS) version II, mechanical ventilation, acute respiratory distress syndrome (ARDS), shock, vasopressors, coma, renal replacement therapy and length of mechanical ventilation; ": SAPS II, mechanical ventilation, ARDS, shock, vasopressors, coma, renal replacement therapy, length of mechanical ventilation, age, acute leukaemia, bone marrow transplantation, non-Hodgkin lymphoma, solid tumour and type of admission

Previous studies have shown similar findings in surgical patients, with decreased mortality in centres having high volumes of cardiac or cancer surgery patients [26, 27]. Recently, KAHN et al. [16] have shown that hospital volume was associated with outcome in patients receiving mechanical ventilation. However, to the current authors' knowledge, this association has not been previously investigated in critically ill haematological patients with ARF. Given the large number of causes of ARF in haematological patients and the frequent combination of multiple causes in individual patients, greater clinical experience might lead to better patient management [10]. In particular, identification of the cause of ARF is associated with improved survival [11, 14, 28] and might benefit from greater clinical experience. Although the use of noninvasive mechanical ventilation and close collaboration with haematological consultants may help to manage these patients [28, 29], neither variable was independently associated with mortality in the present study, suggesting that intensive care specialists may acquire the skills needed to achieve optimal management provided they see a sufficient number of patients with haematological malignancies and ARF. In haematological patients with ARF, the number of ICU admissions is rising and life-sustaining treatments (most notably mechanical ventilation) are increasingly used [6, 8]. The findings of the present study show that mortality is closely associated with the use of mechanical ventilation, renal replacement therapy and vasopressors. Further studies are needed to investigate volume effects in patients with each type of organ failure managed in the ICU.

The current study has many limitations. First, it was performed in a single country. Previous studies have shown that haematological patients are often denied ICU admission based on guidelines from learned societies [30-32]. However, guidelines are applied in a uniform manner across industrialised countries [33]. Secondly, only critically ill haematological patients with ARF were investigated, and the findings may not apply to other populations. Previous studies focused on ARF in all ICU patients. The mechanisms underlying ARF are particularly complex in patients with haematological malignancies, which might leave more room for clinical experience to affect outcomes [11, 16, 34]. ARF is the main reason for ICU admission of haematological patients and mechanical ventilation is the leading predictor of death $[8,9,14]$. Thirdly, it was not possible to distinguish between allogeneic and autologous bone marrow transplantation, whose outcomes differed markedly in earlier studies $[6,12,13,35]$. However, recipients of allogeneic bone marrow transplant, who have poorer outcomes, are probably admitted to high-volume ICUs. ARF usually occurs early after allogeneic bone marrow transplant, so that the patient is generally admitted to the ICU located in the same hospital as the transplant unit. A higher proportion of allogeneic bone marrow transplant recipients would be expected to increase mortality rates, thereby masking a beneficial effect of volume on survival; however, mortality was lower in high-volume ICUs. Finally, only ICU outcome was recorded.

The results of the present study suggest that clinician experience or specific processes of care common to highvolume centres may be associated with outcomes of haematology patients with acute respiratory failure. Additional research is needed to clarify the mechanisms underlying the volumeoutcome relationship. Knowledge of these mechanisms would help to design programmes for improving outcomes in lowvolume intensive care units or aid in the referral of patients to specialised centres.

\section{REFERENCES}

1 Brenner H. Long-term survival rates of cancer patients achieved by the end of the 20th century: a period analysis. Lancet 2002; 360: 1131-1135.

2 Coiffier B, Lepage E, Briere J, et al. CHOP chemotherapy plus rituximab compared with $\mathrm{CHOP}$ alone in elderly patients with diffuse large-B-cell lymphoma. $N$ Engl J Med 2002; 346: 235-242.

3 O'Brien SG, Guilhot F, Larson RA, et al. Imatinib compared with interferon and low-dose cytarabine for newly diagnosed chronic-phase chronic myeloid leukemia. N Engl J Med 2003; 348: 994-1004.

4 Nachman JB, Sather HN, Sensel MG, et al. Augmented post-induction therapy for children with high-risk acute lymphoblastic leukemia and a slow response to initial therapy. N Engl J Med 1998; 338: 1663-1671.

5 Bruno B, Rotta M, Patriarca F, et al. A comparison of allografting with autografting for newly diagnosed myeloma. N Engl J Med 2007; 356: 1110-1120. 
6 Khassawneh BY, White P Jr, Anaissie EJ, Barlogie B, Hiller FC. Outcome from mechanical ventilation after autologous peripheral blood stem cell transplantation. Chest 2002; 121: 185-188.

7 Lecuyer L, Chevret S, Thiery G, Darmon M, Schlemmer B, Azoulay E. The ICU trial: a new admission policy for cancer patients requiring mechanical ventilation. Crit Care Med 2007; 35: 808-814.

8 Kress JP, Christenson J, Pohlman AS, Linkin DR, Hall JB. Outcomes of critically ill cancer patients in a university hospital setting. Am J Respir Crit Care Med 1999; 160: 1957-1961.

9 Soares M, Salluh JI, Spector N, Rocco JR. Characteristics and outcomes of cancer patients requiring mechanical ventilatory support for $>24$ hrs. Crit Care Med 2005; 33: 520-526.

10 Azoulay E, Schlemmer B. Diagnostic strategy in cancer patients with acute respiratory failure. Intensive Care Med 2006; 32: 808-822.

11 Azoulay E, Thiery G, Chevret S, et al. The prognosis of acute respiratory failure in critically ill cancer patients. Medicine (Baltimore) 2004; 83: 360-370.

12 Groeger JS, White P Jr, Nierman DM, et al. J Clin Oncol 1999; 17: 991-997.

13 Pene F, Aubron C, Azoulay E, et al. Outcome of critically ill allogeneic hematopoietic stem-cell transplantation recipients: a reappraisal of indications for organ failure supports. J Clin Oncol 2006; 24: 643-649.

14 Hilbert G, Gruson D, Vargas F, et al. Noninvasive ventilation in immunosuppressed patients with pulmonary infiltrates, fever, and acute respiratory failure. $N$ Engl J Med 2001; 344: 481-487.

15 Halm EA, Lee C, Chassin MR. Is volume related to outcome in health care? A systematic review and methodologic critique of the literature. Ann Intern Med 2002; 137: 511-520.

16 Kahn JM, Goss CH, Heagerty PJ, Kramer AA, O’Brien CR, Rubenfeld GD. Hospital volume and the outcomes of mechanical ventilation. $N$ Engl J Med 2006; 355: 41-50.

17 Annane D, Aegerter P, Jars-Guincestre MC, Guidet B. Current epidemiology of septic shock: the CUB-Rea Network. Am J Respir Crit Care Med 2003; 168: 165-172.

18 Le Gall JR, Lemeshow S, Saulnier F. A new Simplified Acute Physiology Score (SAPS II) based on a European/North American multicenter study. JAMA 1993; 270: 2957-2963.

19 Spiegelhalter DJ. Handling over-dispersion of performance indicators. Qual Saf Health Care 2005; 14: 347-351.

20 Panageas KS, Schrag D, Russell Localio A, Venkatraman ES, Begg CB. Properties of analysis methods that account for clustering in volume-outcome studies when the primary predictor is cluster size. Stat Med 2007; 26: 2017-2035.

21 Panageas KS, Schrag D, Riedel E, Bach PB, Begg CB. The effect of clustering of outcomes on the association of procedure volume and surgical outcomes. Ann Intern Med 2003; 139: 658-665.

22 Peto R, Pike MC, Armitage P, et al. Design and analysis of randomized clinical trials requiring prolonged observation of each patient. II. Analysis and examples. Br J Cancer 1977; 35: 1-39.

23 Peto R, Pike MC, Armitage P, et al. Design and analysis of randomized clinical trials requiring prolonged observation of each patient. I. Introduction and design. Br J Cancer 1976; 34: 585-612.

24 D'Agostino RB Jr. Propensity score methods for bias reduction in the comparison of a treatment to a nonrandomized control group. Stat Med 1998; 17: 2265-2281.

25 Rosenbaum PR, Rubin DB. Difficulties with regression analyses of age-adjusted rates. Biometrics 1984; 40: 437-443.

26 Showstack JA, Rosenfeld KE, Garnick DW, Luft HS, Schaffarzick RW, Fowles J. Association of volume with outcome of coronary artery bypass graft surgery. Scheduled versus nonscheduled operations. JAMA 1987; 257: 785-789.

27 Begg CB, Cramer LD, Hoskins WJ, Brennan MF. Impact of hospital volume on operative mortality for major cancer surgery. JAMA 1998; 280: 1747-1751.

28 Hilbert G, Gruson D, Vargas F, et al. Bronchoscopy with bronchoalveolar lavage via the laryngeal mask airway in high-risk hypoxemic immunosuppressed patients. Crit Care Med 2001; 29: 249-255.

29 Larche J, Azoulay E, Fieux F, et al. Improved survival of critically ill cancer patients with septic shock. Intensive Care Med 2003; 29: 1688-1695.

30 Sprung CL, Geber D, Eidelman LA, et al. Evaluation of triage decisions for intensive care admission. Crit Care Med 1999; 27: 1073-1079.

31 Azoulay E, Pochard F, Chevret S, et al. Compliance with triage to intensive care recommendations. Crit Care Med 2001; 29: 2132-2136.

32 Guidelines for intensive care unit admission, discharge, and triage. Task Force of the American College of Critical Care Medicine, Society of Critical Care Medicine. Crit Care Med 1999; 27: 633-638.

33 Thiery G, Azoulay E, Darmon M, et al. Outcome of cancer patients considered for intensive care unit admission: a hospital-wide prospective study. J Clin Oncol 2005; 23: 4406-4413.

34 Azoulay E, Afessa B. The intensive care support of patients with malignancy: do everything that can be done. Intensive Care Med 2006; 32: 3-5.

35 Afessa B, Tefferi A, Hoagland HC, Letendre L, Peters SG. Outcome of recipients of bone marrow transplants who require intensive-care unit support. Mayo Clin Proc 1992; 67: 117-122. 